JED

24,1

80

Received 13 September 2020 Revised 23 December 2020 Accepted 17 January 2021

\section{A business-cycle model with monopolistically competitive firms and Calvo wages: lessons for Bulgaria}

\author{
Aleksandar Vasilev \\ University of Lincoln, Brayford Campus, Lincoln, UK
}

\begin{abstract}
Purpose - The author augments an otherwise standard business-cycle model with a rich government sector and adds monopolistic competition in the product market and rigid prices, as well as rigid wages a la Calvo (1983) in the labor market.

Design/methodology/approach - This specification with the nominal wage rigidity, when calibrated to Bulgarian data after the introduction of the currency board (1999-2018), allows the framework to reproduce better observed variability and correlations among model variables and those characterizing the labor market in particular. Findings - As nominal wage frictions are incorporated, the variables become more persistent, especially output, capital stock, investment and consumption, which help the model match data better, as compared to a setup without rigidities.

Practical implications - The findings suggest that technology shocks seem to be the dominant source of economic fluctuations, but nominal wage rigidities as well as the monopolistic competition in the product market, might be important factors of relevance to the labor market dynamics in Bulgaria, and such imperfections should be incorporated in any model that studies cyclical movements in employment and wages. Originality/value - The computational experiments performed in this paper suggest that wage rigidities are a quantitatively important model ingredient, which should be taken into consideration when analyzing the effects of different policies in Bulgaria, which is a novel result.
\end{abstract}

Keywords Business cycles, Monopolistic competition, Rigid (Calvo) prices, Rigid (Calvo) nominal wages Paper type Research paper

\section{Introduction}

As shown in Vasilev (2009), the standard real-business-cycle (RBC) model does not capture well model dynamics for Bulgaria. In other words, an important aspect from the real world is missing from the model setup. One explanation for the model failure along the labor market dimension could be the way product markets are modeled; In other words, the perfectcompetition assumption that imposed everywhere in the firm problem in the RBC model might be too restrictive for a transition economy such as Bulgaria. Instead, as demonstrated in Lozev et al. (2011) and Paskaleva (2016), imperfections in the product and factor markets are observed in Bulgaria, together with the presence of price- and wage rigidities, and those patterns should be taken as stylized facts in theoretical models.

In light of this evidence, in this paper we take all those phenomena seriously and incorporate those rigidities in our modeling strategy, which effectively leads to the adoption of the New Keynesian (NK) approach [1], which departs from perfect competition in goods and factors market; as a result, the prices of the factors of production no longer will equal their

\section{JEL Classification - D43, D58, E32}

(C) Aleksandar Vasilev. Published in Journal of Economics and Development. Published by Emerald Publishing Limited. This article is published under the Creative Commons Attribution (CC BY 4.0) licence. Anyone may reproduce, distribute, translate and create derivative works of this article (for both commercial and non-commercial purposes), subject to full attribution to the original publication and authors. The full terms of this licence may be seen at http://creativecommons.org/licences/by/4.0/legalcode 
marginal products. In addition, instead of a stand-in firm, there will be imperfect competition in the intermediate goods firms, and the differentiated intermediate goods will be then combined into a final good, which is produced by a perfectly competitive firm [2]. We can then compare and contrast how a model with rigidities compares to the standard $\mathrm{RBC}$ model without rigidities, when it comes to capturing the dynamics of aggregate labor market variables.

Another important difference from the RBC model is that in the setup in this model the prices of production inputs depend on the elasticity of substitution between the differentiated intermediate goods, which in turn reflects the market power of monopolistically competitive firms to set prices. The distortion driven by the industry structure pushes the prices of labor and capital below their marginal products. More specifically, as shown in Rotemberg and Woodford (1995), the higher the market power of monopolistic firms, the higher the mark-up and as a result, the greater the difference between the marginal product of labor and capital and their prices [3]. In addition, with imperfect competition in the output market, a technology shock affecting the marginal product of capital and labor leads to lower reaction of both the real wage rate and the real interest rate (compared to the perfectly competitive environment). As a result, the owners of the two factors of production will perceive a smaller effect from the productivity shock and that will drive down the use of labor and capital and that would lead to lower output at intermediateand final-good level. In turn, the model no longer generates efficient allocations in equilibrium.

Another important novelty in this paper, which distinguishes the model setup from the standard NK model, would be the presence of rigidities in the wage determination process a la Erceg et al. (2000), Canzoneri et al. (2005) and Christiano et al. (2005). The stickiness in nominal wages is an important ingredient in the transmission of technology shocks and a rigidity which could potentially generate employment and wage fluctuations similar to the ones exhibited in Bulgarian data [4]. Importantly, relative to the rest of the NK literature, we allow for the capital accumulation motive to work alongside nominal rigidities. In the absence of restraint on capital (in the form of investment adjustment costs) and in the absence of active monetary policy, which is the case of Bulgaria, the neoclassical mechanisms seems to dominate quantitatively, with the nominal rigidities being only secondary in importance. In other words, nominal rigidities - despite being a relevant feature of reality - are not the primary factor behind the observed business-cycle fluctuations in Bulgaria.

Overall, allowing for nominal wage rigidities in the model improves the model performance against data, and in addition, this extended setup marginally dominates the standard RBC model framework without wage frictions, e.g. Vasilev (2009, 2019). Therefore, the computational experiments performed in this paper for Bulgaria in the period 1999-2018 [5] suggest that Calvo wages are a quantitatively important model ingredient, which should be taken into consideration when analyzing the effects of different policies. This is a contribution in itself, as this is the first dynamic general equilibrium model with Calvo wages done for Bulgaria, which-following Canova (2007) - has been subjected to a variety of statistical tests. Overall, micro-founded theoretical dynamic general equilibrium models are therefore to be considered as very important devices in the macro modelers' toolboxes, as those setups provide the necessary disciplining of data and allows researchers to discriminate between different alternative explanation, as well as break any observational equivalence problems, such as the ones pertaining to labor market dynamics [6].

The rest of the paper is organized as follows: section 2 describes the model framework and defines the decentralized monopolistically competitive equilibrium system. Section 3 discusses the calibration procedure, and section 4 presents the steady-state model solution. Sections 5 proceeds with the out-of-steady state dynamics of model variables and compared the simulated second moments of theoretical variables against their empirical counterparts. Section 6 concludes the paper.

\section{Model setup}

There is a continuum of ex-ante identical one-member households distributed uniformly on the unit interval and indexed by $j$. Final output is obtained through the aggregation of
Model with competitive firms and Calvo wages 
JED

24,1

82

intermediate good outputs, in an environment of perfect competition and can be used for household consumption, investment or government purchases. In contrast, in the intermediate goods sector, there is monopolistic competition with free entry, which means that each intermediate good is produced by a single monopolistic firm, which has market power and sets the price of the particular good they produce at a mark-up above their marginal cost. Lastly, the government is levying taxes on consumption, labor and capital income in order to finance spending on government purchases and lump-sum government transfers.

\subsection{Households' problem}

Household $j$ maximizes the expected discounted utility, which is of the form [7]

$$
U=E_{t} \sum_{t=0}^{\infty} \beta^{t}\left\{\frac{c_{t}^{1-\sigma}}{1-\sigma}-\frac{h_{t}^{1+\varphi}}{1+\varphi}\right\},
$$

where $E_{t}$ is the expectations operator as of period $t, 0<\beta<1$ denotes the discount factor, $c_{t}$ is consumption of household $j$ in period $t, h_{t}$ are the hours worked by household $j$ in period $t, \sigma$ is the relative risk aversion parameter (and the inverse of the intertemporal elasticity of substitution parameter), and parameter $\varphi$ denotes the curvature of the function capturing the disutility of hours worked.

The household starts with a unit endowment of time in each time period, and a positive endowment of physical capital, $k_{0}$, in period 0 , which is rented to the firm at the nominal rental rate $R_{t}$, that is, before-tax capital income equals $R_{t} k_{t}$. Therefore, each household can decide to invest in capital to augment the capital stock, which evolves according to the following law of motion:

$$
k_{t+1}=i_{t}+(1-\delta) k_{t}
$$

where $0<\delta<1$ is the depreciation rate of physical capital.

In addition to the rental income, each household owns an equal share of the final-goodproducing firm and thus has a legal claim to the firms' nominal profit, $\Pi_{t}$. Household $j$ 's period $t$ budget constraint is then

$$
P_{t}\left[\left(1+\tau^{c}\right) c_{t}+k_{t+1}-(1-\delta) k_{t}\right]=\left(1-\tau^{y}\right)\left[W_{t} h_{t}+R_{t} k_{t}+\Pi_{t}\right]+P_{t} g_{t}^{t},
$$

where $P_{t}$ is the aggregate price index, $\tau^{c}, \tau^{y}$ are consumption and income tax rate, respectively, and $g_{t}^{t}$ are per household government transfers.

The problem faced by each household is then to choose $\left\{c_{t}, h_{t}, k_{t+1}, W_{t}\right\}_{t=0}^{\infty}$ to maximize utility subject to budget constraint [8]. The first-order conditions for the allocations are as follows:

$$
\begin{gathered}
c_{t}: c_{t}^{-\sigma}=\lambda_{t} P_{t}\left(1+\tau^{c}\right) \\
h_{t}: h_{t}^{\varphi}=\lambda_{t} W_{t}\left(1-\tau^{y}\right) \\
k_{t+1}: \lambda_{t} P_{t}=\beta E_{t} \lambda_{t+1}\left[(1-\delta) P_{t+1}+\left(1-\tau^{y}\right) R_{t+1}\right] \\
T V C: \lim _{t \rightarrow \infty} \beta^{t} \lambda_{t} k_{t+1}=0 .
\end{gathered}
$$

The interpretation of the optimality conditions above is standard: the first states that at the margin, optimal consumption is characterized by the balance between the benefit of extra consumption utility and the cost in terms of shadow price of wealth. The second equation balances the disutility of extra work and the benefit in terms of extra income, weighted by 
consumption utility. The third equation, the so-called Euler equation, describes how capital should be allocated in any two congruent periods. The last condition, the "Transversality condition," is a boundary constraint, in order to rule out explosive solution paths.

In addition, since labor can be a differentiated product among households, this implies that households have some market power when setting wages. As in Christiano et al. (2005) and Canzoneri et al. (2005), each household supplies differentiated labor services in a market structure of monopolistic competition. These labor services are rented to a representative firm that aggregates these different types of labor $h_{j}$ into a single labor input $H$. As in Junior (2016), the labor-aggregating firm is assumed to use the following constant elasticity of substitution (CES) technology:

$$
H_{t}=\left(\int_{0}^{1} h_{j, t}^{\frac{\psi_{W}-1}{\psi_{W}}} d j\right)^{\frac{\psi W W}{\psi W-1}}
$$

where $\psi_{W}$ is the elasticity of substitution between differentiated labor services and $h_{j, t}$ is the amount of differentiated labor hours supplied by household $j$. Each type of labor hours $j$ is paid for with a nominal wage $W_{j, t}$. The problem of the labor-aggregating firm is then to maximize its static profit:

$$
\max _{h_{j, t}} W_{t} H_{t}-\int_{0}^{1} W_{j, t} h_{j, t} d j
$$

subject to the aggregation constraint above, or

$$
\max _{h_{j, t}} W_{t}\left(\int_{0}^{1} h_{j, t}^{\frac{\psi_{W}-1}{\psi_{W}}} d j\right)^{\frac{\psi_{W}}{\psi W^{-1}}}-\int_{0}^{1} W_{j, t} h_{j, t} d j
$$

The first-order condition for each type of differentiated labor services is

$$
W_{t}\left(\frac{\psi_{W}}{\psi_{W}-1}\right)\left(\int_{0}^{1} h_{j, t}^{\frac{\psi_{W}-1}{\psi_{W}}} d j\right)^{\frac{\psi_{W}}{\psi_{W}-1}}\left(\frac{\psi_{W}-1}{\psi_{W}}\right) h_{j, t}^{\frac{\psi_{W}-1}{\psi_{W}}-1}-W_{j, t}=0
$$

or,

$$
W_{t}\left(\int_{0}^{1} h_{j, t}^{\frac{\psi_{W}-1}{\psi_{W}}} d j\right)^{\frac{1}{\psi_{W}-1}} h_{j, t}^{-\frac{1}{\psi_{W}}}-W_{j, t}=0
$$

Next, noting that we can express aggregate hours as follows:

$$
H_{t}^{\frac{1}{\psi_{W}}}=\left(\int_{0}^{1} h_{j, t}^{\frac{\psi_{W}-1}{\psi_{W}}} d j\right)^{\frac{1}{\psi_{W}-1}}
$$

Model with competitive firms and Calvo wages 
JED

24,1

so we can replace it in the following equation:

$$
W_{t} H_{t}^{\frac{1}{\psi_{W}}} h_{j, t}^{-\frac{1}{\psi_{W}}}-W_{j, t}=0
$$

After some algebra, we can express the demand for $h_{j}$ as follows:

$$
h_{j, t}=H_{t}\left(\frac{W_{t}}{W_{j, t}}\right)^{\psi_{W}}
$$

Substitute now this expression back into aggregate hours to solve for the aggregate wage rate as a function of household-specific wage rates

$$
W_{t}=\left(\int_{0}^{1} W_{j, t}^{1-\psi_{W}} d j\right)^{\frac{1}{1-\psi_{W}}}
$$

In terms of the wage rigidity, in each period, $1-\theta_{W}$ households, chosen independently and at random, optimally define/set their wages in nominal terms. The remaining households, $\theta_{W}$, follow a wage stickiness rule a la Calvo (1983) and keep the same wage level as the previous period, or, $W_{j, t}=W_{j, t-1}$. In particular, the $1-\theta_{W}$ fraction of households that can choose wage levels in period $t$ knows that, even setting optimal nominal wage $W_{j . t}^{*}$ for the period, it faces a $\theta_{W}^{N}$ probability of these wages remaining fixed for $N$ future period. When household $j$ chooses $W_{j, t}^{*}$ to solve the following problem [9]

$$
\max _{W_{j, t}^{*}} E_{t} \sum_{t=0}^{\infty}\left(\beta \theta_{W}\right)^{t}\left[\ldots-\frac{h_{t}^{1+\varphi}}{1+\varphi}-\lambda_{t}\left(\ldots-W_{j}, t^{*} h_{t}\right)\right]
$$

s.t.

$$
h_{t}=H_{t}\left(\frac{W_{t}}{W_{j, t}}\right)^{\psi_{W}}
$$

Substituting the expression into the objective function

$$
\max _{W_{j, t}^{*}} E_{t} \sum_{t=0}^{\infty}\left(\beta \theta_{W}\right)^{t}\left[\ldots-\frac{1}{1+\varphi}\left[H_{t}\left(\frac{W_{t}}{W_{j, t}}\right)^{\psi_{W}}\right]^{1+\varphi}-\lambda_{t}\left(\ldots-W_{j, t}^{*} H_{t}\left(\frac{W_{t}}{W_{j, t}}\right)^{\psi_{W}}\right)\right]
$$

After some algebraic manipulations, and using that $\lambda_{t}=c_{t}^{-\sigma} / P_{t}$, we can derive the expression for the optimal wage equation set by household $j$ :

$$
W_{j, t}^{*}=\left(\frac{\psi_{W}}{\psi_{W}-1}\right) E_{t} \sum_{t=0}^{\infty}\left(\beta \theta_{W}\right)^{t} c_{t}^{\sigma} h_{t}^{\varphi} P_{t}
$$

As $1-\theta_{W}$ fraction of households chooses the same nominal wages, $W_{j . t}^{*}=W_{t}^{*}$, and the mass of remaining households, $\theta_{W}$, set their wage equal to the nominal wage observed in the previous period. Thus, the aggregate nominal wage can be expressed as

$$
\begin{gathered}
W_{t}^{1-\psi_{W}}=\int_{0}^{\theta_{W}} W_{t-1}^{1-\psi_{W}} d j+\int_{\theta_{W}}^{1} W_{t}^{* 1-\psi_{W}} d j \\
W_{t}^{1-\psi_{W}}=\left[j W_{t-1}^{1-\psi_{W}}\right]_{0}^{\theta_{W}}+\left[W_{t}^{* 1-\psi_{W}}\right]_{\theta_{W}}^{1}
\end{gathered}
$$




$$
W_{t}^{1-\psi_{W}}=\theta_{W} W_{t-1}^{1-\psi_{W}}+\left(1-\theta_{W}\right) W_{t}^{* 1-\psi_{W}},
$$

Model with competitive

hence the aggregate nominal wage rule is:

$$
W_{t}=\left[\theta_{W} W_{t-1}^{1-\psi_{W}}+\left(1-\theta_{W}\right) W_{t}^{* 1-\psi_{W}}\right]^{\frac{1}{1-\psi_{W}}}
$$

\subsection{Firms}

The modeling approach of the industry structure in the setup follows Dixit and Stiglitz (1977), with a continuum of differentiated goods. In turn, these differentiated goods are then aggregated into a single final goods, which is consumed by the households. Each firm produces a single intermediate good that the final producer then uses as an input in the production of the final good via a CES output aggregator function. The final good producer takes prices as given, while intermediate good producers have power over setting their own prices.

2.2.1 Final goods production sector (retail). The functional form chosen for the aggregation technology is

$$
Y_{t}=\left(\int_{0}^{1} Y_{j, t}^{\frac{\psi-1}{\psi t}} d j\right)^{\frac{\psi}{\psi-1}}
$$

where $Y_{t}$ is aggregate output (the product of the retailer) in period $t$, and $Y_{j, t}, j \in[0,1]$ is the output of intermediate (wholesale) good $j$, and $\psi>1$ denotes the elasticity of substitution between the differentiated wholesale goods.

Let $P_{j, t}$ denote the nominal price of wholesale good $j$, the price of each wholesale good is taken as a given by retail firms. The problem faced by each retail firm is then to

$$
\max _{Y_{j, t}} P_{t} Y_{t}-\int_{0}^{1} P_{j, t} Y_{j, t} d j
$$

s.t. (22), or when plugging that expression back into the objective function, to

$$
\max _{Y_{j, t}} P_{t}\left(\int_{0}^{1} Y_{j, t}^{\frac{\psi-1}{\psi}} d j\right)^{\frac{\psi}{\psi-1}}-\int_{0}^{1} P_{j, t} Y_{j, t} d j
$$

Taking the first-order condition and after some algebra we obtain

$$
Y_{j, t}=Y_{t}\left(\frac{P_{t}}{P_{j, t}}\right)^{\psi} .
$$

In other words, the individual demand is proportional to aggregate demand and inversely proportional to relative price level. Now substitute this expression back into aggregate output to obtain the expression for the price of the final (retail) goods in term of the prices of the intermediate goods:

which is also the aggregate price index.

$$
P_{t}=\left(\int_{0}^{1} P_{j, t}^{1-\psi} d j\right)^{\frac{1}{1-\psi}},
$$


JED

24,1

86

2.2.2 Intermediate goods production sector (wholesale). As pointed out earlier, each wholesale firms sell their differentiated goods to the stand-in retail (final-goods) firm. Intermediate-good producers will be assumed to possess some market power and will have some power in setting the price of their product (facing a downward-sloping demand for their product). In addition, it will be assumed that fixed (entry or period) costs do not exist [10]. Since the retailer has constant-returns-to-scale technology, its marginal cost is independent of quantity produced. Furthermore, the marginal cost function coincides with the average cost function, and total cost equals the product of marginal cost time quantity. Net, the retail firm's problem can be split in two parts. In the first, the prices of capital and labor are taken as given, and the firm minimizes total cost subject to the production function (the technology constraint), or

$$
\min _{h_{t}, k_{t}} W_{t} h_{t}+R_{t} k_{t}
$$

s.t

$$
Y_{t}=A_{t} k_{t}^{\alpha} h_{t}^{1-\alpha}
$$

The first-order conditions are

$$
\begin{gathered}
h_{t}:(1-\alpha) \mu_{t} A_{t} k_{t}^{\alpha} h_{t}^{-\alpha}=W_{t} \\
k_{t}: \alpha \mu_{t} A_{t} k_{t}^{\alpha-1} h_{t}^{1-\alpha}=R_{t},
\end{gathered}
$$

where $\mu_{t}$ is the Lagrange multiplier attached to the constraint. With $\mu_{t}=M C_{j, t}$ the equation above become

$$
\begin{gathered}
h_{t}=(1-\alpha) M C_{j, t} \frac{Y_{j, t}}{W_{t}} \\
k_{t}=\alpha M C_{j, t} \frac{Y_{j, t}}{R_{t}}
\end{gathered}
$$

The expressions above are the optimal demand for the two inputs (capital and labor) by each wholesale firm. Deriving the total and marginal cost function can be done from the dual problem-the profit maximization one:

$$
\max _{h_{t}, k_{t}} \pi_{t}=A_{t} k_{t}^{\alpha} h_{t}^{1-\alpha} P_{j, t}-W_{t} h_{t}-R_{t} k_{t}
$$

FOCs:

$$
\begin{gathered}
k_{t}: R_{t}=\alpha \frac{Y_{j, t}}{k_{t}} \\
h_{t}: W_{t}=(1-\alpha) \frac{Y_{j, t}}{h_{t}}
\end{gathered}
$$

After some algebra, we arrive at the following expression: [11]

$$
M C_{j, t}=\frac{1}{A_{t}}\left(\frac{W_{t}}{1-\alpha}\right)^{1-\alpha}\left(\frac{R_{t}}{\alpha}\right)^{\alpha}
$$

Next, the second stage of the problem of the wholesale firm $j$ is optimally setting the price of its product. This firm decides how much to produce in each period a la Calvo (1983). More specifically, in each period, each wholesale firm has a $\theta$ probability of keeping the price of its 
good unchanged in the next period $\left(P_{j . t}=P_{j, t-1}\right)$ and a $1-\theta$ probability of optimally setting its price. Therefore, the problem of a wholesale firm $j$ that is able to reset the price of its good is

$$
\max _{P_{j, t}^{*}} E_{t} \sum_{t=0}^{\infty}(\beta \theta)^{t}\left(P_{j, t}^{*} Y_{j, t}-T C_{j, t+i}\right)
$$

s.t. demand constraint, or

$$
\max _{P_{j, t}^{*}} E_{t} \sum_{t=0}^{\infty}(\beta \theta)^{t}\left(P_{j, t}^{*} Y_{t}\left(\frac{P_{t}}{P_{j, t}}\right)^{\psi}-Y_{t}\left(\frac{P_{t}}{P_{j, t}}\right)^{\psi} M C_{j, t+i}\right)
$$

The first-order condition (after some algebra)

$$
P_{j, t}^{*}=\left(\frac{\psi}{\psi-1}\right) E_{t} \sum_{t=0}^{\infty}(\beta \theta)^{t} M C_{j, t}
$$

Note that all wholesale firms that fix their price have the same mark-up on the same marginal cost. Thus, in all periods, $P_{j, t}^{*}$ is the same price for all the $1-\theta$ firms that set their prices. Following the argument in Junior (2016), the aggregate price level is

$$
\begin{aligned}
& P_{t}^{1-\psi}=\int_{0}^{\theta} P_{t-1}^{1-\psi} d j+\int_{\theta}^{1} P_{t}^{* 1-\psi} d j \\
& P_{t}^{1-\psi}=\left[j P_{t-1}^{1-\psi}\right]_{0}^{\theta}+\left[j P_{t}^{* 1-\psi}\right]_{\theta}^{1} \\
& P_{t}^{1-\psi}=\theta P_{t-1}^{1-\psi}+(1-\theta) P_{t}^{* 1-\psi} \\
& P_{t}=\left[\theta P_{t-1}^{1-\psi}+(1-\theta) P_{t}^{* 1-\psi}\right]^{\frac{1}{1-\psi}}
\end{aligned}
$$

Note that since there is a continuum of intermediate good producers, and the share that can reset its price (and the group that cannot) is chosen randomly, regardless of when each firm last altered its price. As a result, the distribution of prices among firms does not change between periods.

\subsection{Government}

In the model setup, the government is levying taxes on labor and capital income, as well as consumption in order to finance spending on government purchases and government transfers. The government budget constraint is as follows: [12]

$$
\tau^{c} c_{t}+\tau^{y}\left(w_{t} h_{t}+r_{t} k_{t}\right)=g_{t}^{t}+g_{t}^{c}
$$

Tax rates and government consumption-to-output ratio would be chosen to match the average share in data, and government transfers would be determined residually.

\subsection{Stochastic process}

Total factor productivity, $A_{t}$, is assumed to follow $\mathrm{AR}(1)$ processes in logs, in particular

$$
\ln A_{t+1}=\left(1-\rho_{a}\right) \ln A_{0}+\rho_{a} \ln A_{t}+\epsilon_{t+1}^{a},
$$

where $A_{0}>0$ is steady-state level of the total factor productivity process, $0<\rho_{a}<1$ is the 
JED

24,1

88

first-order autoregressive persistence parameter and $\epsilon_{t}^{a} \sim \ddot{i i d N}\left(0, \sigma_{a}^{2}\right)$ are random shocks to the total factor productivity progress. Hence, the innovations $\epsilon_{t}^{a}$ represent unexpected changes in the total factor productivity process.

\subsection{Dynamic monopolistically competitive equilibrium (DMCE)}

Given the processes followed by the stochastic process $\left\{A_{t}\right\}_{t=0}^{\infty}$, average tax rates $\left\{\tau^{c}, \tau^{y}\right\}$, endowments $k_{0} \forall j$, the decentralized dynamic competitive equilibrium is a list of sequences $\left\{c_{t}, i_{t}, h_{t}\right\}_{t=0}^{\infty}$, a sequence of government purchases and transfers $\left\{g_{t}^{c}, g_{t}^{t}\right\}_{t=0}^{\infty}$, price level sequence $\left\{P_{t}\right\}_{t=0}^{\infty}$ and prices $\left\{w_{t}, r_{t}\right\}_{t=0}^{\infty}$ such that (1) each household $j$ maximizes its utility function subject to its budget constraint, (2) the representative final-good firm maximizes profit; (3) intermediate-good firms maximize profit; (4) government budget is balanced in each period and (5) all markets clear.

\section{Data and model calibration}

To calibrate the model to Bulgarian data, we will focus on the period after the introduction of the currency board (1999-2018). Annual data on output, consumption and investment was collected from National Statistical Institute (2019), while the real interest rate is taken from Bulgarian National Bank Statistical database (2019). The calibration strategy described in this section follows a long-established tradition in modern macroeconomics: first, the discount factor, $\beta=0.982$, is set to match the steady-state capital to output ratio in Bulgaria over the period, which is $k / y=3.491$. The labor share parameter, $\alpha=0.429$, was computed as the average value of labor income in aggregate output over the period 1999-2018. The depreciation rate of physical capital in Bulgaria, $\delta=0.05$, was estimated as the average depreciation rate over the period 1999-2018. The curvature parameters of consumption and leisure components in the household's utility function are set to $\sigma=2$ and $\varphi=1.5$ in order to generate plausible value for aggregate labor supply elasticity. The average income tax rate was set to $\tau^{y}=0.1$, and the tax rate on consumption, $\tau^{c}=0.2$, is set to their values over the period 1999-2018. Next, due to the lack of more recent data, the elasticity of substitution between differentiated intermediate goods was set to $\psi=5$ to generate the average mark-up of 25 percent estimated by Dobrinsky et al. (2006) for Bulgaria. Similarly, the elasticity of substitution between differentiated labor services was set to $\psi_{W}=7$ to generate a wedge between marginal utility of consumption and the marginal disutility of leisure of 17 percent, which is the average inter-industry wage difference. The price stickiness parameter was set to $\theta=0.74$ following Paskaleva (2016)'s estimate on the share of firms that do not change prices. Similarly, as in Lozev et al. (2011) the wage stickiness parameter, $\theta_{W}=0.68$, was set to the share of firms that set wages to the previous period wages [13]. Lastly, the process followed by total factor productivity is estimated from the detrended series by running an AR (1) regression and saving the residuals. Table 1 below summarizes the values of all model parameters used in the paper.

\section{Steady-state}

Once the values of model parameters were obtained, [14] the steady-state equilibrium system solved, the "big ratios" can be compared to their averages in Bulgarian data. The results are reported in Table 2 below. The model matches consumption-to-output ratio by construction. The investment and government purchases ratios are free variables and are also closely approximated. The shares of income are also identical to those in data, which is an artifact of the assumptions imposed on functional form (Cobb-Douglas) of the aggregate production function. The after-tax return, net of depreciation, $\tilde{r}=\left(1-\tau^{y}\right) r-\delta$, is also very closely captured by the model. 


\begin{tabular}{|c|c|c|c|c|}
\hline Parameter & Value & Description & Method & Model with \\
\hline$\beta$ & 0.982 & Discount factor & Calibrated & firms and \\
\hline$\alpha$ & 0.429 & Capital share & Data average & $11111 \mathrm{~s}$ ailu \\
\hline $1-\alpha$ & 0.571 & Labor share & Calibrated & Calvo wages \\
\hline$\delta$ & 0.050 & Depreciation rate on physical capital & Data average & \\
\hline$\varphi$ & 1.500 & Curvature, disutility of work & Set & \\
\hline$\sigma$ & 2.000 & Curvature, utility of consumption & Set & 89 \\
\hline$h$ & 0.333 & Share of time spent working & Data average & \\
\hline$\tau^{c}$ & 0.200 & VAT/consumption tax rate & Data average & \\
\hline$\tau^{y}$ & 0.100 & Average tax rate on income & Data average & \\
\hline$\theta$ & 0.740 & Price stickiness parameter & Data average & \\
\hline$\theta_{W}$ & 0.680 & Wage stickiness parameter & Data average & \\
\hline$\psi$ & 5.000 & Elasticity of substitution, intermediate goods & Calibrated & \\
\hline$\psi_{W}$ & 7.000 & Elasticity of substitution, differentiated labor & Calibrated & \\
\hline$\rho_{a}$ & 0.701 & AR(1) parameter, total factor productivity & Estimated & Table 1 \\
\hline$\sigma_{a}$ & 0.044 & st.dev, total factor productivity & Estimated & Model parameters \\
\hline
\end{tabular}

\begin{tabular}{lllll}
\hline Variable & Description & Data & Model & \\
\hline$c / y$ & Consumption-to-output ratio & 0.674 & 0.674 & \\
$i / y$ & Investment-to-output ratio & 0.201 & 0.175 & \\
$g^{c} / y$ & Government cons-to-output ratio & 0.159 & 0.151 & Table 2. \\
$w h / y$ & Labor income-to-output ratio & 0.571 & 0.571 & Data averages and \\
$r k / y$ & Capital income-to-output ratio & 0.429 & 0.429 & long-run solution \\
$\tilde{r}$ & After-tax net return on capital & 0.056 & & \\
\hline
\end{tabular}

\section{Out-of-steady state model dynamics}

Since the model does not have an analytical solution for the equilibrium behavior of variables outside their steady-state values, we need to solve the model numerically. This is done by loglinearizing the original equilibrium (non-linear) system of equations around the steady-state. This transformation produces a first-order system of stochastic difference equations. First, we study the dynamic behavior of model variables to an isolated shock to the total factor productivity process, and then we fully simulate the model to compare how the second moments of the model perform when compared against their empirical counterparts. Special focus is put on the cyclical behavior of labor market variables.

\subsection{Impulse response analysis}

This subsection documents the impulse responses of model variables to a $1 \%$ surprise innovation to technology. The impulse response function (IRFs) are presented in Figure 1 on the next page against the IRFs from a model without nominal price and wage rigidities [15]. As a result of the one-time unexpected positive shock to total factor productivity, output increases. This expands the availability of resources in the economy, so consumption, investment and government consumption also increase upon impact. As a result of the increase in productivity, the real interest rate increases as well, and households increase their capital accumulation. Wages also increase in real terms more with Calvo wages and prices. Importantly, compared to the perfectly competitive case, the effects over aggregate output is smaller upon impact, as demonstrated in Junior (2016) and Torres (2013), since the inefficiencies produced by imperfect competition at intermediate level itself reduce the effect of the technology shock. In addition, with nominal wage frictions, model variables become 
JED

90

Figure 1.

Impulse responses to a

$1 \%$ surprise

innovation in

technology
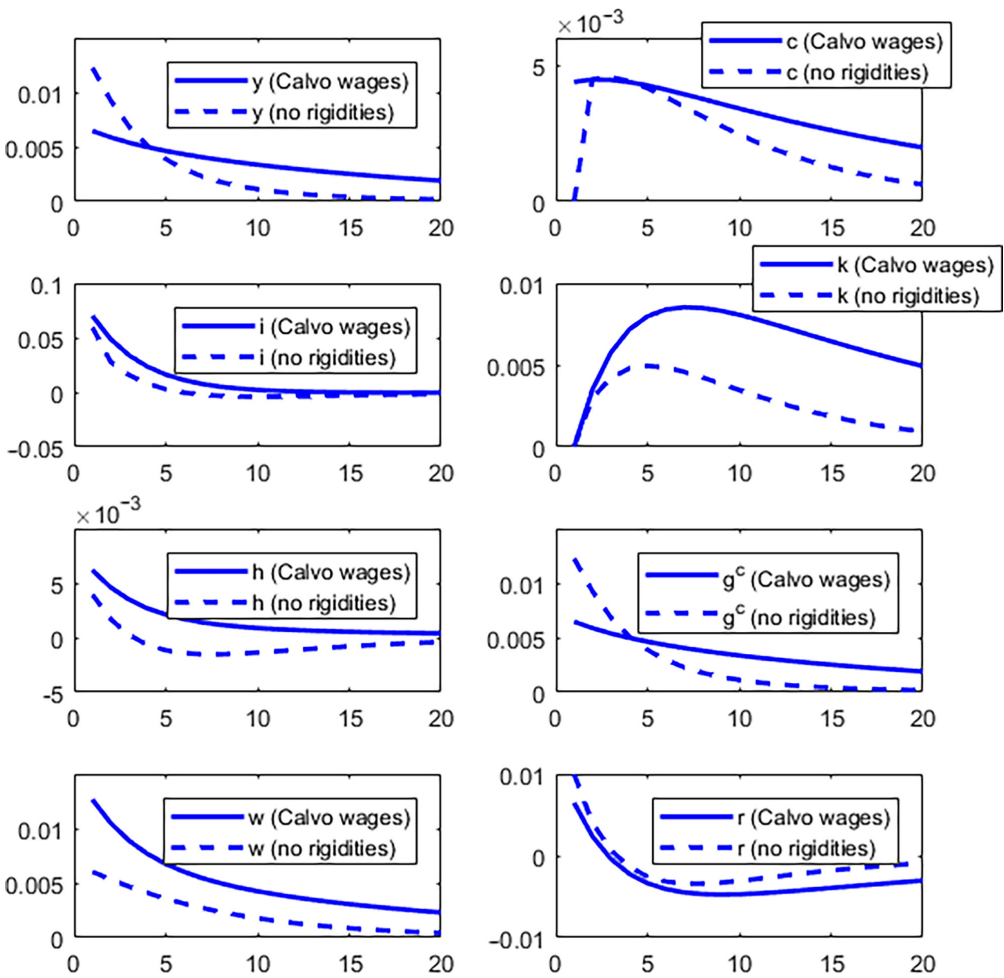

more persistent, especially output, capital stock and consumption. The "adjustment stickiness" of wages also causes households' labor supply to initially increase more than in other models, e.g. the standard RBC and NK models without wage frictions, as shown in Junior (2016). Physical capital also varies more due to its complementarity with labor.

Over time, as the effect of the shock waves, the return on capital decreases, which drives down investment and capital accumulation back to their old steady-state values. The other model variables return to their old values in a monotone manner as well as the effect of the one-time surprise innovation in technology dies out.

\subsection{Simulation and moment-matching}

We will now simulate the model 10,000 times for the length of the data horizon. Both empirical and model simulated data are detrended using the Hodrick and Prescott (1980) filter. Table 3 on the next page summarizes the second moments of data (relative volatilities to output and contemporaneous correlations with output) versus the same moments computed from the model-simulated data at annual frequency. We compare side by side the moments from a model with nominal rigidities versus a model with no rigidities and perfect competition ("benchmark model"). The two models match quite well the absolute volatility of output. However, both models slightly overestimates the variability in consumption and more substantially that of investment [16]. Still, the model is qualitatively consistent with the finding the consumption varies less than output, and investment varies more than output. By construction, government spending in the model varies as much as in data. 


\begin{tabular}{|c|c|c|c|c|}
\hline & Data & $\begin{array}{c}\text { Model } \\
\text { (With calvo wages) }\end{array}$ & $\begin{array}{l}\text { Benchmark model } \\
\text { (w/o rigidities) }\end{array}$ & $\begin{array}{l}\text { Model with } \\
\text { competitive }\end{array}$ \\
\hline$\sigma_{y}$ & 0.05 & 0.05 & 0.05 & \\
\hline$\sigma_{c} / \sigma_{y}$ & 0.55 & 0.92 & 0.84 & Calvo wages \\
\hline$\sigma_{i} / \sigma_{y}$ & 1.77 & 5.25 & 2.36 & \\
\hline$\sigma_{g} / \sigma_{y}$ & 1.21 & 1.00 & 1.00 & \\
\hline$\sigma_{h} / \sigma_{y}$ & 0.63 & 0.53 & 0.29 & 91 \\
\hline$\sigma_{w} / \sigma_{y}$ & 0.83 & 1.49 & 0.81 & \\
\hline$\sigma_{y / h} / \sigma_{y}$ & 0.86 & 1.49 & 0.81 & \\
\hline $\operatorname{corr}(c, y)$ & 0.85 & 0.97 & 0.89 & \\
\hline $\operatorname{corr}(i, y)$ & 0.61 & 0.53 & 0.80 & \\
\hline $\operatorname{corr}(g, y)$ & 0.31 & 1.00 & 1.00 & \\
\hline $\operatorname{corr}(h, y)$ & 0.49 & 0.73 & 0.33 & Table \\
\hline $\operatorname{corr}(w, y)$ & -0.01 & 0.94 & 0.96 & Business-cycle \\
\hline $\operatorname{corr}(h, y / h)$ & -0.14 & 0.86 & 0.96 & moments \\
\hline
\end{tabular}

With respect to the labor market variables, the variability of employment predicted by the model with Calvo wages is much closer to that in data, compared to the benchmark model without rigidities; however, the variability of wages in the Calvo-wage model is much higher than that in data. Next, in terms of contemporaneous correlations, the model with Calvowages slightly over-predicts the pro-cyclicality of the main aggregate variablesconsumption and government consumption. This, however, is a common limitation of this class of models. In addition, the model with Calvo wages is a bit better than the alternative. Along the labor market dimension, the contemporaneous correlation of employment with output is of the right sign, but the model predicts it to be quite strong, while in data the linear relationship is more moderate. With wages, the model predicts strong cyclicality, while wages in data are acyclical. The same is true with the contemporaneous correlation between productivity and hours. Again, the Calvo model is marginally better than the alternative setup without rigidities along this dimension of data. In the next subsection, we investigate the dynamic correlation between labor market variables at different leads and lags, thus evaluating how well the model matches the phase dynamics among variables. In addition, the autocorrelation functions (ACFs) of empirical data, obtained from an unrestricted VAR (1) are put under scrutiny and compared and contrasted to the simulated counterparts generated from the model.

\subsection{Auto- and cross-correlation}

This subsection discusses the ACFs and cross-correlation functions (CCFs) of the major model variables. The coefficients empirical ACFs and CCFs at different leads and lags are presented in Table 4 against the simulated AFCs and CCFs. For the sake of brevity, we present only results for the model with Calvo wages only. Following Canova (2007), this comparison is used as a goodness-of-fit measure. As seen from Table 4 on the next page, the model compares well vis-a-vis data. Empirical ACFs for output and investment are slightly outside the confidence band predicted by the model, while the ACFs for total factor productivity and household consumption are well-approximated by the model.

The persistence of labor market variables are also well-described by the model dynamics: the ACFs unemployment and wages are close to the simulated ones until the third lag. Same holds true for output and investment. The ACF for consumption is well-captured only until the first lag. Overall, the model with persistence a la Calvo (1983) in nominal wages generates the right persistence in model variables and is able to respond to the criticism in Nelson and Plosser (1982), Cogley and Nason (1995) and Rotemberg and Woodford (1996), who argue that 


\begin{tabular}{|c|c|c|c|c|c|c|}
\hline \multirow{3}{*}{$\begin{array}{l}\mathrm{JE} \\
24,\end{array}$} & & & & & & \\
\hline & \multirow[b]{2}{*}{ Method } & \multirow[b]{2}{*}{ Statistic } & \multicolumn{4}{|c|}{$K$} \\
\hline & & & 0 & 1 & 2 & 3 \\
\hline \multirow[b]{5}{*}{92} & Data & $\operatorname{corr}\left(u_{t}, u_{t-k}\right)$ & 1.000 & 0.765 & 0.552 & 0.553 \\
\hline & \multirow[t]{2}{*}{ Model } & $\operatorname{corr}\left(u_{t}, u_{t-k}\right)$ & 1.000 & 0.818 & 0.629 & 0.442 \\
\hline & & (s.e.) & $(0.000)$ & $(0.035)$ & $(0.063)$ & $(0.084)$ \\
\hline & Data & $\operatorname{corr}\left(h_{t}, h_{t-k}\right)$ & 1.000 & 0.484 & 0.009 & 0.352 \\
\hline & \multirow[t]{2}{*}{ Model } & $\operatorname{corr}\left(h_{t}, h_{t-k}\right)$ & 1.000 & 0.818 & 0.629 & 0.442 \\
\hline & & (s.e.) & $(0.000)$ & $(0.035)$ & $(0.063)$ & $(0.084)$ \\
\hline & Data & $\operatorname{corr}\left(y_{t}, y_{t-k}\right)$ & 1.000 & 0.810 & 0.663 & 0.479 \\
\hline & Model & $\operatorname{corr}\left(y_{t}, y_{t-k}\right)$ & 1.000 & 0.815 & 0.625 & 0.438 \\
\hline & Data & $\begin{array}{l}\text { (s.e.) } \\
\operatorname{corr}\left(a_{t}, a_{t-t_{1}}\right)\end{array}$ & $\begin{array}{l}(0.000) \\
1.000\end{array}$ & $\begin{array}{c}(0.037) \\
0.702\end{array}$ & $\begin{array}{c}(0.001) \\
0.449\end{array}$ & $\begin{array}{c}(0.091) \\
0.277\end{array}$ \\
\hline & \multirow{2}{*}{ Model } & $\operatorname{corr}\left(a_{t}, a_{t-k}\right)$ & 1.000 & 0.814 & 0.624 & 0.437 \\
\hline & & (s.e.) & $(0.000)$ & $(0.038)$ & $(0.070)$ & $(0.096)$ \\
\hline & Data & $\operatorname{corr}\left(c_{t}, c_{t-k}\right)$ & 1.000 & 0.971 & 0.952 & 0.913 \\
\hline & \multirow[t]{2}{*}{ Model } & $\operatorname{corr}\left(c_{t}, c_{t-k}\right)$ & 1.000 & 0.815 & 0.625 & 0.438 \\
\hline & & (s.e.) & $(0.000)$ & $(0.037)$ & $(0.067)$ & $(0.091)$ \\
\hline & Data & $\operatorname{corr}\left(i_{t}, i_{t-k}\right)$ & 1.000 & 0.810 & 0.722 & 0.594 \\
\hline & \multirow[t]{2}{*}{ Model } & $\operatorname{corr}\left(i_{t}, i_{t-k}\right)$ & 1.000 & 0.816 & 0.624 & 0.434 \\
\hline \multirow{4}{*}{$\begin{array}{l}\text { Table } 4 \text {. } \\
\text { Autocorrelations for } \\
\text { Bulgarian data and the } \\
\text { model economy }\end{array}$} & & (s.e.) & $(0.000)$ & $(0.038)$ & $(0.069)$ & $(0.095)$ \\
\hline & \multirow{3}{*}{$\begin{array}{l}\text { Data } \\
\text { Model }\end{array}$} & $\operatorname{corr}\left(w_{t}, w_{t-k}\right)$ & 1.000 & 0.760 & 0.783 & 0.554 \\
\hline & & $\operatorname{corr}\left(w_{t}, w_{t-k}\right)$ & 1.000 & 0.816 & 0.627 & 0.441 \\
\hline & & (s.e.) & $(0.000)$ & $(0.036)$ & $(0.065)$ & $(0.087)$ \\
\hline
\end{tabular}

this class of models do not have a strong internal propagation mechanism besides the strong persistence in the TFP process. Furthermore, the Calvo nominal wage mechanism dominates other non-Walrasian models such as Vasilev (2016, 2017b). Next, as seen from Table 5 on the next page, over the business cycle, in data labor productivity leads employment. The model nominal wage persistence, however, cannot account for this fact. In this model, as well as in the standard RBC model a technology shock can be regarded as a factor shifting the labor demand curve, while holding the labor supply curve constant. Therefore, the effect between employment and labor productivity is only a contemporaneous one. Still, the model with nominal wage persistence a la Calvo (1983) is a clear improvement over the perfectlycompetitive labor market paradigm used in Vasilev $(2009,2019)$.

\section{Conclusions}

We augment an otherwise standard DSGE model with a rich government sector and add monopolistic competition in the product market and rigid prices, as well as rigid wages a la Calvo (1983) in the labor market. This specification with the nominal wage rigidity, when

\begin{tabular}{llccccccc}
\hline & & \multicolumn{7}{c}{$k$} \\
& Statistic & -3 & -2 & -1 & 0 & 1 & 2 & 3 \\
\hline Data & $\operatorname{corr}\left(h_{t},(y / h)_{t-k}\right)$ & -0.342 & -0.363 & -0.187 & -0.144 & 0.475 & 0.470 & 0.346 \\
Model & $\operatorname{corr}\left(h_{t},(y / h)_{t-k}\right)$ & 0.034 & 0.033 & 0.029 & 0.960 & 0.030 & 0.034 & 0.035 \\
& $($ s.e. & $(0.732)$ & $(0.643)$ & $(0.531)$ & $(0.098)$ & $(0.534)$ & $(0.645)$ & $(0.734)$ \\
Data & corr $\left(h_{t}, w_{t-k}\right)$ & 0.355 & 0.452 & 0.447 & 0.328 & -0.040 & -0.390 & -0.57 \\
Model & $\operatorname{corr}\left(h_{t}, w_{t-k}\right)$ & 0.034 & 0.033 & 0.029 & 0.960 & 0.030 & 0.034 & 0.035 \\
& (s.e.) & $(0.732)$ & $(0.643)$ & $(0.531)$ & $(0.098)$ & $(0.534)$ & $(0.645)$ & $(0.734)$ \\
& & & & & & & &
\end{tabular}

Table 5.

Dynamic correlations Data for Bulgarian data and Mode the model economy $\operatorname{corr}\left(h_{t}, w_{t-k}\right)$ 
calibrated to Bulgarian data after the introduction of the currency board (1999-2018), allows the framework to reproduce better observed variability and correlations among model variables and those characterizing the labor market in particular. These results suggest that technology shocks seem to be the dominant source of economic fluctuations, but nominal wage rigidities a la Calvo (1983), as well as the monopolistic competition in the product market, might be important factors of relevance to the labor market dynamics in Bulgaria, and such imperfections should be incorporated in any model that studies cyclical movements in employment and wages. Therefore, the empirical findings that the theoretical setup with Calvo wages fits data better, can be interpreted as a validation of the model and a rejection of the model without nominal wage rigidities and perfect competition in the case of Bulgarian data for the period 1999-2018. Overall, micro-founded theoretical dynamic general equilibrium models are therefore to be considered as very important devices in the macro modellers' toolboxes, as those setups provide the necessary disciplining of data and allows researchers to discriminate between different alternative explanation, as well as break any observational equivalence problems, e.g. in cases when similar impulse responses of model variables are produced as a result of a technology shock, such as ones generated by an atheoretical VARs. As a result of the monopolistic competition the effects of technology shocks on output are smaller upon impact, as compared to the perfectly competitive case, since the inefficiencies produced by imperfect competition itself reduce the effect of the technology shock. More specifically, the deviation from a perfectly competitive paradigm leads to an inefficient allocation of labor and capital inputs (market failures), resulting in a lower equilibrium level for the economy and lower effects from a productivity shock. As nominal wage frictions are incorporated, the variables become more persistent, especially output, capital stock and consumption. Still, the model suffers from some of the usual shortcomings inherent in this class of DSGE models. As a suggestion for future research, the model might be extended to accommodate other important (and real) frictions in the labor market, possibly along the lines of Vasilev (2016, 2017b, 2018).

\section{Notes}

1. This modeling approach was initially developed by Rotemberg (1982), Blanchard and Kiyotaki (1987) and Rotemberg and Woodford $(1992,1995)$, among others.

2. In other words, the final stage is identical to the standard RBC model.

3. As pointed out in Torres (2013), this is a direct consequence of the assumption that the elasticity of substitution between differentiated goods is strictly greater than unity.

4. In order to accommodate those, it will be also assumed that labor services are differentiated among households. This assumption implies that households also possess certain market power in setting their nominal wages. This assumption could be easily rationalized with the presence of labor unions, as well as certain provisions in the Bulgarian Labor code, which protect workers' interests in labor disputes with employers. Both explanations are empirically plausible in Bulgaria, as demonstrated in Paskaleva (2016).

5. This period was chosen as it is a period of macroeconomic stability.

6. "Observational equivalence problems" occur in cases when similar impulse responses of model variables are produced as a result of a technology shock, such as ones generated by an a-theoretical unrestricted or structural VARs.

7. To simplify notation, we will suppress the $j$ index and use smaller case letters to denote individual allocations and capital letters for aggregate quantities.

8. We postpone the discussion of optimal wage-setting until later.

9. As in Junior (2016), we keep only the relevant terms in the problem below.
Model with competitive firms and Calvo wages 
JED

24,1

94

10. Actually, that assumption is not that relevant-we can have an equivalent representation with fixed "period costs" and free entry, which leads the firm to set price above mc to cover the amount of the fixed costs and have 0 profit. This is the representation utilized in Torres (2013).

11. Note that the expression below is consistent with the requirement that

$$
M C_{j, t}=T C_{j, t} / Y_{j, t} .
$$

12. Given that there is a unit mass of households, individual and total allocations are identical.

13. Al those values are consistent with the values of those parameters in the literature for the US and other EU countries.

14. The steady-state results for a model with no rigidities and perfect competition are very close and thus not presented.

15. The results are insensitive to the degree of wage persistence, as captured by parameter $\psi w$.

16. This shortcoming of the models could be explained by structural factors in Bulgaria, such as privatization of state assets and the short annual time series for Bulgaria. In addition, public investment in infrastructure has been also substantial in the last few years due to the EU accession funds.

\section{References}

Blanchard, O. and Kiyotaki, N. (1987), "Monopolistic competition and the effects of aggregate demand", American Economic Review, Vol. 77 No. 4, pp. 647-666.

Bulgarian National Bank (2019), "BNB statistical Database", available at: www.bnb.bg (accessed 9 November 2019).

Calvo, G. (1983), "Staggered prices in a utility-maximizing framework", Journal of Monetary Economics, Vol. 12, pp. 383-98.

Canova, F. (2007), Methods for Applied Macroeconomic Research, Princeton University Press, Princeton, NJ.

Canzoneri, M., Cumby, R. and Diba, B. (2005), "Price and wage inflation targeting: variations on a theme by Erceg, henderson and levin", in Orphanides, A. and Reifscheneider, D. (Eds), Models and Monetary Policy: Research in the Tradition of Dale Henderson, Richard Porter and Peter Tinsley, Washington, Board of Governors of the Federal Reserve System.

Christiano, L., Eichenbaum, M. and Evans, C. (2005), "Nominal rigidities and the dynamic effects of a shock to monetary policy", Journal of Political Economy, Vol. 113 No. 1, pp. 1-45.

Cogley, T. and Nason, J.M. (1995), "Output dynamics in real-business-cycles", American Economic Review, Vol. 85 No. 3, pp. 492-511.

Dixit, A. and Stiglitz, J. (1977), "Monopolistic competition and optimum product diversity", American Economic Review, Vol. 67 No. 3, pp. 297-308.

Dobrinsky, R., Korosi, G., Markov, N. and Halpern, L. (2006), "Price mark-ups and returns to scale in imperfect markets: Bulgaria and Hungary”, Journal of Comparative Economics, Vol. 34, pp. 92-110.

Erceg, C.J., Henderson, D.W. and Levin, A. (2000), "Optimal monetary policy with staggered wage and price contracts”, Journal of Monetary Economics, Vol. 46 No. 2, pp. 281-313.

Junior, C.J.C. (2016), Understanding DSGE Models: Theory and Applications, Vernon Press, Malaga, Spain.

Hodrick, R.J. and Prescott, E.C. (1980), Post-war US Business Cycles: an Empirical Investigation, Unpublished manuscript (Carnegie-Mellon University, Pittsburgh, PA).

Lozev, I., Vladova, Z. and Paskaleva, D. (2011), "Wage-setting behaviour of Bulgarian firms: evidence from survey data”, Bulgarian National Bank Discussion Paper DP/87/2011, Sofia, Bulgaria.

National Statistical Institute (2019), "NSI statistical Database", available at: www.nsi.bg (accessed 8 November 2019). 
Nelson, C.R. and Plosser, C.I. (1982), "Trends and random walks in macroeconomic time series", Journal of Monetary Economics, Vol. 10 No. 2, pp. 139-62.

Paskaleva, D. (2016), "Labour cost and price adjustment practices of Bulgarian firms in the period 2009-2013”, Bulgarian National Bank Discussion Paper DP/101/2016, Sofia, Bulgaria.

Rotemberg, J. (1982), "Monopolistic price adjustment and aggregate output", Review of Economic Studies, Vol. 49 No. 4, pp. 517-31.

Rotemberg, J. and Woodford, M. (1992), "Oligopolistic pricing and the effects of aggregate demand on economic activity”, Journal of Political Economy, Vol. 100 No. 6, pp. 1153-1207.

Rotemberg, J. and Woodford, M. (1995), "Dynamic general equilibrium models with imperfectly competitive product markets", in Cololey, T. (Ed.), Frontiers of Business Cycle Research, Princeton University Press, Princeton, New Jersey.

Rotemberg, J. and Woodford, M. (1996), "Real-business-cycle models and the forecastable movements in output, hours, and consumption", American Economic Review, Vol. 86, pp. 71-89.

Torres, J. (2103), Introduction to Dynamic Macroeconomics General Equilibrium Models, Vernon Press, Malaga, Spain.

Vasilev, A. (2009), "Business cycles in Bulgaria and the Baltic countries: an RBC approach", International Journal of Computational Economics and Econometrics, Vol. 1 No. 2, pp. 148-170.

Vasilev, A. (2016), "Search and matching frictions and business cycle fluctuations in Bulgaria", Bulgarian Economic Papers BEP 03-2016, Center for Economic Theories and Policies, Sofia University St. Kliment Ohridski, Faculty of Economics and Business Administration, Sofia, Bulgaria.

Vasilev, A.Z. (2017b), "A Real-Business-Cycle model with efficiency wages and a government sector: the case of Bulgaria", Central European Journal of Economic Modelling and Econometrics, Vol. 9 No. 4, pp. 359-377.

Vasilev, A. (2018), "A Real-Business-Cycle model with reciprocity in labor relations and fiscal policy: the case of Bulgaria", Journal of Economics and Econometrics, Vol. 61 No. 2, pp. 47-76.

Vasilev, A.Z. (2019), "Are habits important for the propagation of business cycle fluctuations in Bulgaria?”, Central European Journal of Economic Modelling and Econometrics, Vol. 11 No. 3, pp. 133-151.

\section{Further reading}

Vasilev, A. (2015), "Welfare effects of at income tax reform: the case of Bulgaria", Eastern European Economics, Vol. 53 No. 2, pp. 205-220.

Vasilev, A.Z. (2017a), "VAT evasion in Bulgaria: a general-equilibrium approach", Review of Economics and Institutions, Vol. 8 No. 2, pp. 2-17.

Vasilev, A.Z. (2017c), "Business Cycle Accounting: Bulgaria after the introduction of the currency board arrangement (1999-2014)", European Journal of Comparative Economics, Vol. 14 No. 2, pp. 197-219.

\section{Corresponding author}

Aleksandar Vasilev can be contacted at: alvasilev@yahoo.com

For instructions on how to order reprints of this article, please visit our website:

www.emeraldgrouppublishing.com/licensing/reprints.htm

Or contact us for further details: permissions@emeraldinsight.com
Model with competitive firms and

Calvo wages 